\title{
Effectiveness of maggot extractions and secretion (E/S) of Lucilia sericata in reducing wound surface in experimental scalding burn injury
}

\author{
ZAHRA SADAT AMIRI ${ }^{1}$, KAMRAN AKBARZADEH ${ }^{1}$, MASOUMEH DOURAGHI ${ }^{2}$, KHOSROU M. ABDI $^{3}$, \\ ABBAS AGHAEI AFSHAR ${ }^{4}$, JASEM GHAFFARI ${ }^{1}$, RAZIEH SHABANI KORDSHOULI $^{1}$, MORTEZA AKBARI $^{5}$, \\ JAVAD RAFINEJAD ${ }^{1, \varphi}$ \\ ${ }^{1}$ Department of Medical Entomology and Vector Control, School of Public Health, Tehran University of Medical Sciences. Tehran, Iran. \\ vemail jrafinejad@yahoo.com \\ ${ }^{2}$ Division of Microbiology, Department of Pathobiology, School of Public Health, Tehran University of Medical Sciences. Tehran, Iran \\ ${ }^{3}$ Department of Medicinal Chemistry, Faculty of Pharmacy and Pharmaceutical Sciences Research Center, Tehran University of Medical Sciences. \\ Tehran, Iran \\ ${ }^{4}$ Department of Medical Entomology and Vector Control, School of Public Health, Kerman University of Medical Sciences. Kerman, Iran \\ ${ }^{5}$ Department of Public Health, School of Health, Ilam University of Medical Sciences. Ilam, Iran
}

Manuscript received: 18 October 2020. Revision accepted: 23 December 2020.

\begin{abstract}
Amiri ZS, Akbarzadeh K, Douraghi M, Abdi KM, Afshar AA, Ghaffari J, Kordshouli RS, Akbari M, Rafinejad J. 2021. Effectiveness of maggot extractions and secretion $(E / S)$ of Lucilia sericata in reducing wound surface in an experimental scalding burn injury. Nusantara Bioscience 13: 11-15. Lucilia sericata larvae have been successfully used as medicinal larvae for wound healing. This study was performed to evaluate the therapeutic effects of the primary ointment made from excretory-secretory substances of L.sericata larvae on experimental burn wounds on rabbits under laboratory conditions. Extraction of ES from the third stage of L.sericata larvae and antibiogram testing was done. Four rabbits were randomly divided into four groups; three standard third-grade burn wounds were created on the back of each rabbit for intervention groups $(B, D)$ of wounds were used respectively from the original ointment made from ES and ES without accompanying material. Nitrofurazone ointment was used for the positive (C) and placebo ointment was used for the negative (A). On the 21st day, all scars of wounds in groups B and D were separated and the wound was free of infectious tissue, whereas in groups $\mathrm{A}$ and $\mathrm{C}$ that the scars were clinging to the base. The level of the ulcer was significantly lower in the $\mathrm{E} / \mathrm{S}$ intervention group and the infectious tissue was not observed during the treatment of group B and D wounds. Methicillin-resistant Staphylococcus aureus (MRSA) did not show resistance to excretory-secretory substances of L. sericata larvae. The debridement and recovery process was faster in the ES-treated group and the initial ointment than in the control group. The results showed that maggot extractions and secretion $(\mathrm{E} / \mathrm{S})$ of $L$. sericata in reducing wound healing is appropriate for treatment.
\end{abstract}

Keywords: Burn, Lucilia sericata, ointment, secretion-excretion, wounds

\section{INTRODUCTION}

A Necrophagous maggot is the larva of some flies (Order Diptera) that have a beneficial property. They have increasingly being applied to clean wounds by destroying, liquefying, and ingesting only devitalize / necrotic tissue for centuries which is known as maggot therapy (Yan et al. 2018). In this method, larvae of flies Calliphoridae family, including Lucilia sericata (Greenbottle fly) and Calliphora vicina using for wound healing (Yan et al. 2018).

Many people around the world suffer from burn injuries (Mogoşanu and Grumezescu 2014). Burn ulcer is a type of skin injury that often long-term treatment with high economic costs. Moreover, may become infected during treatment and become more painful, instead of gradually improving (Sterling et al. 2010). Burn ulcers are caused mainly by exposure to extra heat, electricity, light, radiation as well as chemical elements. It mostly occurs only on the skin (Murphy and Evans 2012; Sterling et al. 2010). In addition to the local effect on the skin, heat has many general effects on the body. These complications are specific to burn injuries and are not generally seen in wounds caused by other injuries (Tiwari 2012).

Maggots were first used to treat wounds during the American Civil War. However, in 2004 the Food and Drug Administration (FDA) authorized the use of maggots for medical use (Sherman 2005). L. sericata larvae are successfully used as medicinal larvae in wound healing and help the healing process by proteolytic digestion, disinfection of necrotic tissue, and stimulation of active promotion of granulation tissue formation (Steenvoorde et al. 2007). Regardless of the preference of the mode of action, larvae of $L$. sericata initiate their activities in the wound by chemical secretions and excretions (Nigam et al. 2006; Sherman 2014). Maggot extractions and secretion (ES) treatment have been shown to aid the healing process by stimulates the regeneration of blood vessels and also has a proliferative effect on the growth of human endothelial cells (Elshehaby et al. 2017). Many studies have shown evidence that larvae have antimicrobial activity in two ways, including antimicrobial action by ingestion larvae of wound bacteria, which are killed when they enter the larval 
digestive tract also through the antimicrobial activity of secretions and larval excretions, including salivary gland secretions and fecal wastes (Valachova et al. 2013). However, the main mechanisms in wound healing with ES treatment are not yet completely understood, This method became popular around the world for the treatment of chronic and infectious wounds (Hou et al. 2007).

Today, despite advances in technology and healthcare, chronic wound management remains a major challenge and therefore requires alternative methods. This study has been conducted to study excretion/secretions (E/S) of larvae of $L$. sericata on the healing of experimental burn wounds in rabbits.

\section{MATERIALS AND METHODS}

\section{Rearing of flies}

Lucilia sericata was rearing continuously in the fly insectary of Tehran University of Medical Sciences from 2013. The temperature and relative humidity in the insectary were $27 \pm 2^{\circ} \mathrm{C}$ and $50 \pm 10 \%$ respectively. The light/dark regimen was $16 / 8$ hours. The adult flies were fed by sugar, milk powder, palm dates, and water but their larvae fed on the chicken liver for rearing.

\section{Ethical approval}

The ethical committee of Tehran University of Medical Sciences, Iran performed ethical approval using rabbits. (Ethics code: IR.TUMS.SPH.REC.1397.4977)

\section{Extracting of E/S}

As much as 300 (in three equal replicates) of third instar larvae of $L$. sericata with 12-14 millimeters in length were selected to find the average weight of 100 larvae. This weight was used as a standard for selecting larvae for extraction. For extracting 3.7 grams of larvae were selected and washed with normal detergent as the first step. Washing with ddH2O, submerging in $\mathrm{EtOH} 70 \%$ for 30 seconds, and again washing with $\mathrm{ddH} 2 \mathrm{O}$ were the next steps for cleaning the larvae before the extraction process. Extracting of E/S was started with the put of these larvae into a disinfected laboratory beaker and adding 1000 microliter of PBS (Phosphate Buffered Saline). The beaker was covered with a sterile mosquito net and put in the dark area at room temperature for 5 hours. After this time duration, the liquid in the beaker was centrifuged at 10000 $\mathrm{g}$ for 10 minutes. The supernatant, which has been mentioned as pure $\mathrm{E} / \mathrm{S}$, was stored at $-20^{\circ} \mathrm{C}$ for future use.

\section{Protein assay}

Three replicates of extracted E/S of the larvae were assayed with a BCA kit (cat.T9300A) according to manufacturer construction.

\section{Microbial examination of E/S}

The Antimicrobial activity of E/S was tested in vitro using the agar well diffusion method (Scott 1989) and Mueller Hinton Agar medium. Bacterial inoculums that were used for antimicrobial activity were a sensitive strain of Staphylococcus aureus and MRSA (methicillin-resistant $S$. aureus ). A dilution of $0.5 \mathrm{McFarland}$ of this bacteria was spread on Mueller Hinton agar using a sterile swab, which has moistened in the solution. Wells of $6 \mathrm{~mm}$ were punched in the inoculated plate, which was filled with six dilutions of E/S (1, 1/2, 1/4, 1/8, and 1/16). Also, PBS and Cefoxitin Antibiotic were used for negative and positive control, respectively. PBS was used for making dilutions of $\mathrm{E} / \mathrm{S}$ as well as filling of at least one of the wells in each plate as the negative control. As much as 80 microliters of each dilution were pipetted in the wells as treatment. Three replicates of each dilution were tested. The growth inhibition zone around each well was measured after 24 hours of incubation at $37^{\circ} \mathrm{C}$. This test was performed out in triplicate and zones of inhibition were measured in $\mathrm{mm}$. scale.

\section{Experimental ointment}

For better stability and permeability of E/S, an experimental ointment has prepared by mixing $1 \mathrm{gr}$ of urea and 10gr of Eucerine with the E/S extract.

\section{Producing experimental burn injury}

Male rabbits $(n=4$; age, 16-18 months; weight, $2.5 \pm 2$ $\mathrm{kg}$ ) were selected in the Laboratory of Experimental Animals in the School of Public Health of Tehran University of Medical Sciences. The lab had controlled conditions at $25 \pm 2^{\circ} \mathrm{C}$ and a $12 / 12$ dark/light regimen. The animal models had free access to food and water. The Ethical Committee of the School of Public Health of Tehran University of Medical Sciences approved all steps of the project. Ketamine and Xylazine were used for anesthetizing rabbits via intraperitoneal injection with doses of 100 and $50 \mathrm{mg} / \mathrm{kg}$ respectively. Three wounds with about $20 \mathrm{~mm}$ in diameter were produced on the back of the rabbits using hot water after complete anesthetizing, disinfecting by EtOH70\%, and local shaving. Ten seconds were enough to produce each of the 3rd degrees of burn wounds. Treating was started after 24 hours from the time of burning. Each of four rabbits was selected randomly to allocate to one of four testing groups including A, B, C, and D. Groups D and B were treatment groups for treating with pure E/S and experimental ointment respectively. Groups C and A were control groups for treating with Nitrfurazone ointment (as positive control) and placebo (as negative control) respectively. The wounds were left uncovered after each treatment.

\section{Data collecting}

The inspection was done at 24 hours intervals to photographing the wound surfaces and repeating of treatments. Each photo was used for the measurement of the necrotic and granulated tissues by Matlab software. Observations were recorded due to the appearance of the wounds, bad odors as well as any infectious discharge. On the last day of the study untreated rabbit's unconsciousness and disappeared. 


\section{RESULTS AND DISCUSSION}

The average weight of 300 individuals of third larvae with $12-14 \mathrm{~mm}$ in body length was $3.7 \pm 0.2 \mathrm{~g}$. This weight was used for future tests instead of counting 100 larvae for each replicate.

Results of protein assay showed that the average of whole proteins in E/S of 100 individuals of third larvae was $1159.7 \pm 44.7 \mu \mathrm{g} / \mathrm{mL}$

Results of agar well diffusion tests showed that the pure $\mathrm{E} / \mathrm{S}$ is the most effective for removing both sensitive and resistant strains of $S$. aureus. Mean zone inhibition of pure $\mathrm{E} / \mathrm{S}$ were $19.3 \pm 0.58 \mathrm{~mm}$ and $17.6 \pm 0.58 \mathrm{~mm}$ in diameter for sensitive and resistant strains of $S$. aureus respectively (Table 1).

Repeated measure analysis was used for evaluating the trend of reducing the wound surface over time, which can be mentioned as a trend of improvement in all wounds. The analysis showed that the reduction of the wound surface in each group was significant from the first day of starting $(\mathrm{P} \leq 0.001)$. Due to the LSD analysis and comparison of mean wound size in groups over time, wound size changes in the $\mathrm{E} / \mathrm{S}$ group with the negative control group have a significant difference $(\mathrm{P} \leq 0.011)$. (Figure 1).

Pure E/S (purple line), experimental ointment (green line), positive control with nitrofurazone (yellowish line), negative control (blue line).

The covariance Test showed a significant difference in reducing wound surfaces between negative control and each of pure E/S and experimental ointment as well as between positive control and pure E/S (Table 2, Figure 2).

Numerous research has been focused on the antibacterial activity of maggots ES against gram-positive and gram-negative bacteria but the results have been different. The most important effect of burning is the loss of protective function of skin against dangerous pathogenic microorganisms (Murphy and Evans 2012) such as $S$. aureus, Pseudomonas aeruginosa, and some other microorganisms (Van Duin et al. 2016). Therefore the risk of infection is high for burn patients (Coban 2012). The results of this study showed that pure $\mathrm{E} / \mathrm{S}$ is the most effective for removing both sensitive and resistant strains of $S$. aureus (MRSA). Regarding the antibacterial effect of maggots, it was found that the maggot ingests and kill $E$. coli when it passes through the midgut (Mumcuoglu et al. 2001). Thomas et al. (1999) confirmed the antibacterial activity of secretions against a range of bacteria, including $S$. aureus and methicillin-resistant $S$. aureus (MRSA) in a preliminary laboratory study (Thomas et al. 1999).

Long-time hospitalization will increase the risk of infection (Shupp et al. 2010) with special attention to drugresistant infections (Branski et al. 2009). However, in maggot therapy, there is no need for surgery and hospitalization, and compared to other treatment methods has a lower cost.

The results of this study showed that the reduction of the wound surface in each group was significant from the first day $(\mathrm{P} \leq 0.001)$ and wound size changes in the $\mathrm{E} / \mathrm{S}$ group with the negative control group have a significant difference $(\mathrm{P} \leq 0.011)$. In another study, It was found L. sericata larval secretions could modulate the mRNA expression of some wound healing-related genes and contains components that are effective in wound healing (Akbas et al. 2020).

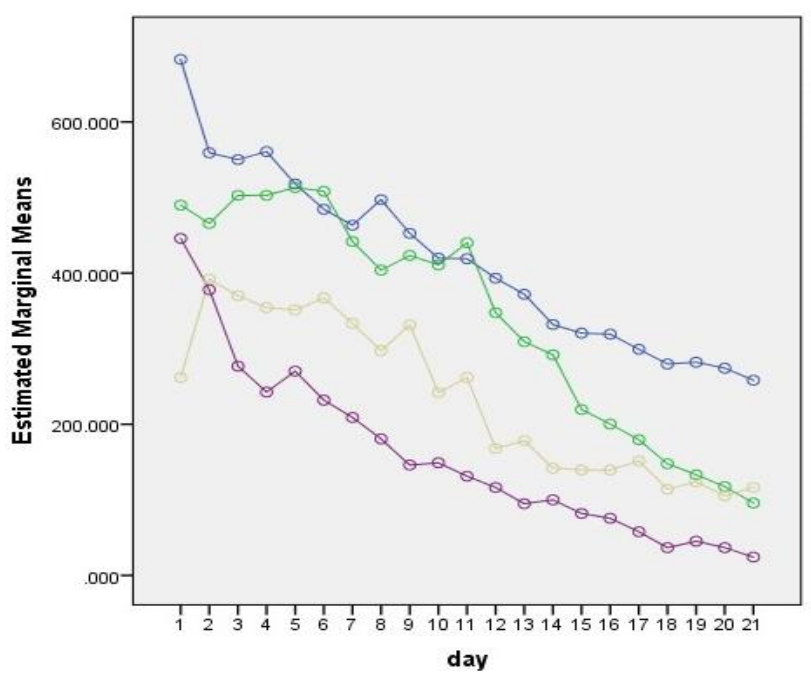

Figure 1. Comparing of average reducing trends in wound surfaces among control groups

Table 1. Zone inhibition of various dilutions of E/S of 100 larvae of $L$. sericata in agar well diffusion test.

\begin{tabular}{|c|c|c|c|c|c|c|}
\hline \multirow{2}{*}{$\begin{array}{c}\text { Type of } \\
\text { Staphylococcus aureus }\end{array}$} & \multirow{2}{*}{ Replicates } & \multicolumn{5}{|c|}{ Dilutions of E/S } \\
\hline & & 1 & $1 / 2$ & $1 / 4$ & $1 / 8$ & $1 / 16$ \\
\hline \multirow[t]{5}{*}{ Sensitive $S$. aureus } & 1 & 19 & 17 & 13 & 9 & 7 \\
\hline & 2 & 19 & 14 & 13 & 10 & - \\
\hline & 3 & 20 & 14 & 10 & 10 & - \\
\hline & Average & 19.33 & 15 & 12 & 9.66 & \\
\hline & $\mathrm{SD}$ & 0.58 & 1.73 & 1.73 & 0.58 & \\
\hline \multirow[t]{5}{*}{ Resistant $S$. aureus } & 1 & 17 & 15 & 11 & 9 & - \\
\hline & 2 & 18 & 12 & 12 & 8 & - \\
\hline & 3 & 18 & 14 & 10 & 8 & - \\
\hline & Average & 17.67 & 13.67 & 11.00 & 8.33 & \\
\hline & $\mathrm{SD}$ & 0.58 & 1.53 & 1.00 & 0.58 & \\
\hline
\end{tabular}


The most important aid for healing burn wounds is wound bed preparation, which has different methods .The standard method for dealing with such wounds is fast and wide debridement with a graft (Madihally et al. 2003). Whatever the method, debridement is an integral part of it; this is possible in both mechanical and chemical (enzymatic) forms. The history of wound enzymatic treatments using plant or bacterial-derived enzymes dates back to about 60 years before World War II (Hafezi et al 2009). The enzymes trypsin, leucine, aminopeptidase, and carboxypeptidases A and B have been isolated from the secretions of L. sericata larvae (Vistnes et al. 1981). Schmidtchen et al. (2003) used animal models to show the secretory properties of maggot $\mathrm{E} / \mathrm{S}$ in resolving necrotic tissue, they also identified several proteases (Schmidtchen et al. 2003).

Debridement should be done in almost all of the burn ulcers for treatment (Mann and Heimbach 1996). Nonselective debridement, which is usual for the treatment of wounds, may damage basement tissues other than necrotic. One of the best selective methods for debridement is maggot therapy (Colin et al. 1996) which has a good background in the healing ulcers caused by burning, chronic infection, diabetes complications, and post-surgical wounds (Wu et al. 2017). In addition to healing wounds, maggot disinfects wounds and stimulates the regenerative process by proteolytic digestion (Nigam et al. 2006).

Managing pain in the treatment of burn wounds is crucial (Mann and Heimbach 1996) which may limit the use of free larvae in maggot therapy by L.sericata (Mumcuoglu et al. 2012) especially for use in burn wounds. Elimination of physical contact can be a solution for solving the painful use of larvae in burn wounds without reducing their effects in debridement and subsequent wound healing.

Larval secretions using deoxyribonuclease (DNAse) can destroy microbial DNA as well as human DNA in necrotic tissues (Brown et al. 2012). Biofilms and biological materials in wounds have become increasingly known as a problem. Therefore, focus on new strategies for the eradication of severe infections associated with biofilm is very important. The presence of small antibacterial agents $(1 \mathrm{kDa})$ in $\mathrm{E} / \mathrm{S}$ showed that against a range of bacteria including $S$. aureus is active (Elshehaby et al. 2017). E/S enzymes can dissolve biofilms and inhibit biofilm growth (Elshehaby et al. 2017; Harris et al. 2009).

The E/S extract from $L$. sericata larvae with its proteolytic properties can be effective in the chemical debridement of burn wounds, the process of debridement, preparation of the wound bed, and treatment. According to the results of this study, we can see a significant change in the treatment of such wounds. The application of the results of this research, due to its experimental and fundamental nature, can be a basis for further research on volunteers or drug manufacturing. The use of proteolytic enzymes is very extensive and can be used in all wounds that have necrotic tissue and require debridement, including compression, diabetic, and other chronic wounds. It is recommended that further research be continued in this area.

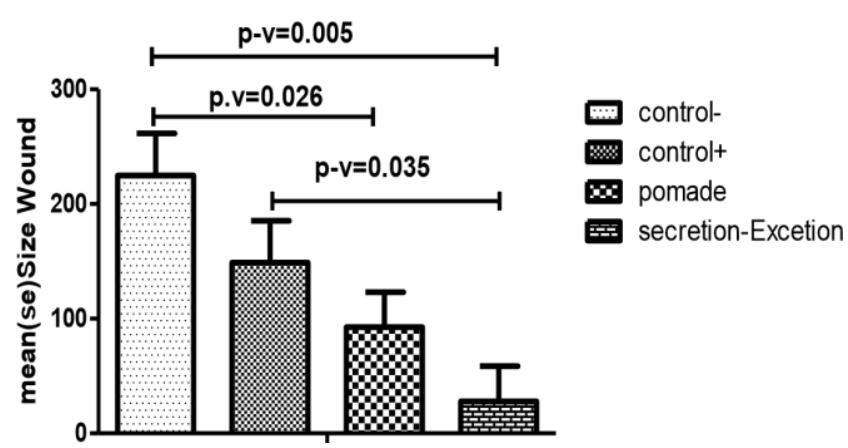

Figure 2. Comparisons of average reduction in wound size at last day of treatment (day 21). 두: pure E/S, $\mathbf{H}$ : experimental ointment, 害: positive control,

Table 2. Comparisons of average reduction in wound size at last day of treatment (Day 21)

\begin{tabular}{llcc}
\hline \multicolumn{1}{c}{ Name groups (A) } & Name group contrastable (B) & Dispute mean & Sig.b \\
\hline Placebo & Ointment & $132.2^{*}$ & .026 \\
& Ointment Nitrofurazone & 75.9 & .238 \\
Pomade & Excretion-Secretion & $196.9^{*}$ & .005 \\
& Placebo & $-132.2^{*}$ & .026 \\
Pomade Nitrofurazone & Ointment Nitrofurazone & -56.2 & .282 \\
& Excretion-Secretion & 64.6 & .179 \\
Excretion-Secretion & Placebo & -75.9 & .238 \\
& Ointment & 56.2 & .282 \\
& Excretion-Secretion & $120.9^{*}$ & .035 \\
& Placebo & $-196.9^{*}$ & .005 \\
& Ointment & -64.6 & .179 \\
\end{tabular}




\section{ACKNOWLEDGEMENTS}

We would like to thank the department of microbiology of the school of public health at the Tehran University of Medical Sciences. This study was part of an M.Sc. dissertation funded and supported by Tehran University of Medical Sciences, Iran (Grant no. 9511263002).

\section{REFERENCES}

Akbas F, Ozaydin A, Polat E, Onaran I. 2020. Lucilia sericata larva secretions stimulating wound healing effects on rat dermal fibroblast cells. Rec Nat Prod 14: 340-354.

Branski LK, Al-Mousawi A, Rivero H, Jeschke MG, Sanford AP, Herndon DN. 2009. Emerging infections in burns. Surg Infect 10: 389-397.

Brown A, Horobin A, Blount D, Hill P, English J, Rich A, Williams PM, Pritchard D. 2012. Blow fly Lucilia sericata nuclease digests DNA associated with wound slough/eschar and with Pseudomonas aeruginosa biofilm. Med Vet Entomol 26: 432-439.

Coban YK. 2012. Infection control in severely burned patients. World J Crit Care Med 1: 94-101

Colin D, Kurring P, Quinlan D, Yvon C. 1996. Managing sloughy pressure sores. J Wound Care 5: 444-446.

Elshehaby M, Tony M, Sultan AR, Reheem A, Baset A. 2017. Antibacterial properties of larval secretions of the blowfly, Lucilia sericata (Diptera: Calliphoridae). Egypt Acad J Biol Sci 9: 1-12.

Hafezi F, Elmirad H, Pedram MS. 2009. Determination of the macroscopic effect of kiwi fruit on wound healing in rats (a new effective drug for the treatment of deep chronic wounds). Iran J Surg 17: $1388-1397$

Harris LG, Bexfield A, Nigam Y, Rohde H, Ratcliffe NA, Mack D. 2009. Disruption of Staphylococcus epidermidis biofilms by medicinal maggot Lucilia sericata excretions/secretions. Intl J Artif Organs 32: 555-564.

Hou L, Shi Y, Zhai P, Le G. 2007. Antibacterial activity and in vitro antitumor activity of the extract of the larvae of the housefly (Musca domestica). J Ethnopharmacol 111: 227-231.

Wu JC, Lu RR, Huo R, Fu HB, Song SM. 2012. Maggot therapy for repairing serious infective wound in a severely burned patient. Chin J Traumatol 15: 124-125.

Madihally S, Solomon V, Mitchell R, Van De Water L, Yarmush M, Toner M. 2003. Influence of insulin therapy on burn wound healing in rats. J Surg Res 109: 92-100.

Mann R, Heimbach D. 1996. Prognosis and treatment of burns. West J Med 165:215-220.
Mogoşanu GD, Grumezescu AM. 2014. Natural and synthetic polymers for wounds and burns dressing. Int J Pharm 463: 127-136.

Mumcuoglu K, Davidson E, Avidan A, Gilead L. 2012. Pain related to maggot debridement therapy. J Wound Care 21: 400-405.

Mumcuoglu KY, Miller J, Mumcuoglu M, Friger M, Tarshis M. 2001. Destruction of bacteria in the digestive tract of the maggot of Lucilia sericata (Diptera: Calliphoridae). J Med Entomol 38: 161-166.

Murphy PS, Evans GR. 2012. Advances in wound healing: A review of current wound healing products. Plast Surg Intl 2012: 1-8.

Nigam Y, Bexfield A, Thomas S, Ratcliffe NA. 2006. Maggot therapy: The science and implication for CAM Part I-history and bacterial resistance. Evid. Based Compl Altern Med 3: 223-227.

Schmidtchen A, Wolff H, Rydengard V, Hansson C. 2003. Detection of serine proteases secreted by Lucilia sericata in vitro and during treatment of a chronic leg ulcer. Acta Derm Venereol 83: 310-311.

Sherman RA. 2005. Age-old therapy gets new approval. Adv Skin Wound Care 18: 12-15.

Sherman RA. 2014. Mechanisms of maggot-induced wound healing: What do we know, and where do we go from here?. Evid Based Compl Altern Med 2014: 592419. DOI: 10.1155/2014/592419.

Shupp JW, Pavlovich AR, Jeng JC, Pezzullo JC, Oetgen WJ, Jaskille AD, Jordan MH, Shoham S. 2010. Epidemiology of bloodstream infections in burn-injured patients: A review of the national burn repository. J Burn Care Res 31: 521-528.

Steenvoorde P, Jacobi CE, Van Doorn L, Oskam J. 2007. Maggot debridement therapy of infected ulcers: Patient and wound factors influencing outcome-a study on 101 patients with 117 wounds. Ann R Coll Surg Engl 89: 596-602.

Sterling J, Heimbach D, Gibran N. 2010. Management of the Burn Wound. ACS Surgery: Principles and Practice. Marcell Decker, Hamilton, ON.

Thomas S, Andrews AM, Hay NP, Bourgoise S. 1999. The anti-microbial activity of maggot secretions: results of a preliminary study. J Tissue Viability 9: 127-132.

Tiwari V. 2012. Burn wound: How it differs from other wounds? Indian J Plast Surg 45: 364-372.

Valachova I, Bohova J, Kozanek M, Takac P, Majtan J. 2013. Lucilia sericata medicinal maggots: A new source of antimicrobial compounds. Formatex 2013: 1745-1753.

van Duin D, Strassle PD, DiBiase LM, Lachiewicz AM, Rutala WA, Eitas T, Maile R, Kanamori H, Weber DJ, Cairns BA, Napravnik S, Jones SW. 2016. Timeline of healthcare-associated infections and pathogens after burn injuries. Am J Infect Control 44: 1511-1516.

Vistnes L, Lee R, Ksander G. 1981. Proteolytic activity of blowfly larvae secretions in experimental burns. Surgery 90: 835-841.

Yan L, Chu J, Li M, Wang X, Zong J, Zhang X, Song M, Wang S. 2018. Pharmacological properties of the medical maggot: A novel therapy overview. Evid Based Compl Altern Med 2018: 4934890. DOI: $10.1155 / 2018 / 4934890$ 